\title{
Influence of Pore Structure on Compressive Strength of Cement Mortar
}

\author{
Haitao Zhao, ${ }^{1}$ Qi Xiao, ${ }^{1}$ Donghui Huang, ${ }^{2}$ and Shiping Zhang ${ }^{3}$ \\ ${ }^{1}$ College of Civil and Transportation Engineering, Hohai University, Nanjing 210098, China \\ ${ }^{2}$ China Three Gorges Corporation, Beijing 100038, China \\ ${ }^{3}$ Department of Civil Engineering and Architecture, Nanjing Institute of Technology, Nanjing 211167, China
}

Correspondence should be addressed to Haitao Zhao; zhaohaitao78@163.com

Received 30 December 2013; Accepted 5 February 2014; Published 16 March 2014

Academic Editors: X. Cheng, A. Rodríguez-Castellanos, and J. Zheng

Copyright (C) 2014 Haitao Zhao et al. This is an open access article distributed under the Creative Commons Attribution License, which permits unrestricted use, distribution, and reproduction in any medium, provided the original work is properly cited.

\begin{abstract}
This paper describes an experimental investigation into the pore structure of cement mortar using mercury porosimeter. Ordinary Portland cement, manufactured sand, and natural sand were used. The porosity of the manufactured sand mortar is higher than that of natural sand at the same mix proportion; on the contrary, the probable pore size and threshold radius of manufactured sand mortar are finer. Besides, the probable pore size and threshold radius increased with increasing water to cement ratio and sand to cement ratio. In addition, the existing models of pore size distribution of cement-based materials have been reviewed and compared with test results in this paper. Finally, the extended Bhattacharjee model was built to examine the relationship between compressive strength and pore structure.
\end{abstract}

\section{Introduction}

Natural sand has been traditionally used in mortars and concrete. However, as growing environmental restrictions to the exploitation of sand from riverbeds, an alternative material to produce fine aggregates should be developed. Manufactured fine aggregate then appear as an attractive alternative to natural fine aggregates for cement-based materials. Manufactured sand (MS), in contrast with natural sand (NS), comes from the mechanical crushing of virgin rock, which has angular particle and rough texture. Wakchaure and $\mathrm{BE}[1]$ demonstrated that manufactured sand contains more microfines, which provide a larger area of the interfacial bond zone, and angular shape and rough texture improve the frictional properties that increased the flexural strength of concrete. Some other experiments illustrated that concrete with manufactured sand had good abrasion resistance, chloride ion permeability, freeze-thaw durability, and some other durability [2-4]. In a word, these existing researches had indicated that manufactured sand can be used effectively and economically in concretes designed for a variety of applications.
The pore structure of cement-based materials contains air voids, capillary pores, and gel pores, and the pores are randomly sized, arranged, and connected [5]. It is a well-known fact that porosity is one of the key parameters which directly affect the strength and durability of cementbased materials $[6,7]$. As we all know, a lower porosity in concretes with sufficient binding material content leads to higher strength concretes [8-12]. According to Mindess et al. [13], the traditional classification of pores in concrete, two classes of pores were considered: gel pores $(<10 \mathrm{~nm})$, which are associated with the formation of hydration products, and capillary pores $(10 \mathrm{~nm} \sim 10000 \mathrm{~nm})$, which dominate transport processes. And the dependence of diffusivity of concrete on pore structure attributes mainly to the effect of capillary porosity and connectivity of these capillary pores [14].

To determine the microstructure of cement-based materials, different techniques were developed and each has its own limitations. Chlorides penetration method [15] has no limitation on the size of samples, and surface area and pore structure determined by desorption isotherm demonstrated that the $3 \mathrm{D}$ nondestructive micro-CT technique is limited by their resolution $[16,17]$. Mercury intrusion porosimetry 
(MIP) is based on the premise that a nonwetting liquid (contact angle greater than $90^{\circ}$ ) will only intrude capillaries under pressure according to the Washburn equation. Theories indicated that the MIP technique is an available method to determine the pore size distribution of cementbased materials.

Many pore size distribution models of cement-based materials have been proposed according to MIP experiment results [18-22]. In these models, mean pore diameter, threshold radius, and total porosity are the most crucial parameters describing pore size distribution. Atahan et al. [23] indicated that the mean pore diameter, hydration degree, and threshold radius are the main characteristics of the material which accounts for their permeability properties. Odler and Rößler [6] have prepared cement pastes with different water cement ratios which were hydrated at different temperatures for different ages. They have demonstrated that the main factor influencing strength properties is the porosity. Winslow and Liu [24] investigated the difference of the pore size distribution between the cement paste in concrete and mortar and the plain paste. They showed that there was an additional formation of pores greater in size in mortar and concrete than that of the plain paste, and they considered that these larger pores are present only in the interfacial zone between aggregate and cement paste.

Many researchers have proposed various relationships between strength and porosity of porous materials [812 ]; however, porosity is not the only influential factor on strength. As experimental research indicated, finer pores concrete has higher strength than the coarser one at the same total porosity. So, it is indispensable to research the relationship between the strength and pore structure of cement-based materials $[6,12,24]$.

In this work, the MIP technique was used to investigate the effect of water to cement ratio $(w / c)$ and sand to cement ratio $(s / c)$ on the pore structure of manufactured sand mortar and natural sand mortar. The existing models of pore size distribution of cement-based materials have been reviewed and compared with test results in this investigation. In addition, uniaxial compressive strength was tested and the strength-pore structure relationship of cement mortar has been constructed in this paper.

\section{Experimental Programme}

2.1. Experimental Materials and Mix Proportions. Ordinary Portland cement (ASTM Type I) without mineral additions was used as binder. In this work, 24 mix proportions cement mortar with the $w / c$ of $0.4,0.5,0.6$, and 0.7 were prepared. The fine aggregate was manufactured sand consisting mainly of calcium carbonate and natural river sand composed mostly of quarts. The gradation of the two types of fine aggregate was shown in Figure 1, and the physical characteristic was shown in Table 1. The mix proportion and workability of cementbased mortars are listed in Table 2.

2.2. Strength Measurement. Compressive tests were run on specimens according to ASTM C349. The specimens $(52 \mathrm{~mm}$

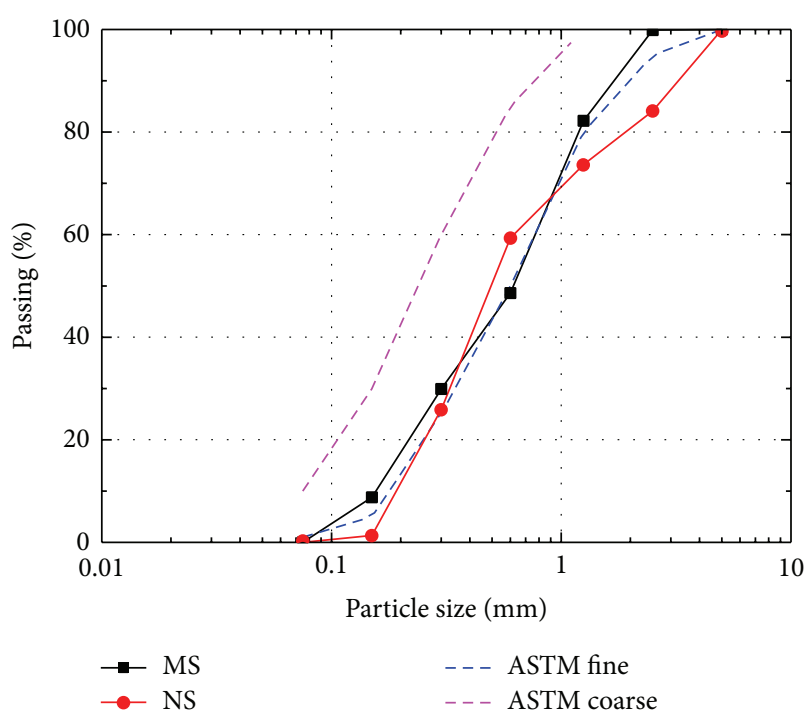

FIGURE 1: Particle size distribution of fine aggregate according to ASTM C-33.

TABLE 1: Summary of the characteristics of the fine aggregate samples tested.

\begin{tabular}{lcccc}
\hline Sample & $\begin{array}{c}\text { Specific } \\
\text { gravity }\end{array}$ & $\begin{array}{c}\text { Bulk density } \\
\left(\mathrm{g} / \mathrm{cm}^{3}\right)\end{array}$ & $\begin{array}{c}\text { Void } \\
(\%)\end{array}$ & $\begin{array}{c}\text { Fineness } \\
\text { modules }\end{array}$ \\
\hline MS & 2.63 & 1.72 & 35.86 & 2.4 \\
NS & 2.53 & 1.65 & 34.78 & 2.6 \\
\hline
\end{tabular}

$\times 100 \mathrm{~mm}$ cylinder) were prepared by drilling cores. $0.4 \mathrm{kN} / \mathrm{s}$ uniform continuous loads were loaded on the specimens using a new SANA hydraulic universal testing machine.

2.3. Determination of Porosity. The total porosity of the mortar samples was estimated from the ratio between the weight of the test sample after curing in an oven at $105^{\circ} \mathrm{C}$ until reaching constant weight, followed by saturation of the sample by immersion in water for 72 hours, according to the ASTM C642-97. This is the fraction of pore volume accessible to water in the mortar. The porosity was calculated using the following equation:

$$
p=\frac{\left(W_{\mathrm{ssd}}-W_{d}\right)}{\left(W_{\mathrm{ssd}}-W_{w}\right)} \times 100 \%,
$$

where $p$ is the porosity (100\%), $W_{\text {ssd }}$ is the specimen weight in the saturated surface-dry (SSD) condition $(g), W_{d}$ is the specimen dry weight until reaching constant weight in oven $(g)$, and $W_{w}$ is the weight of saturated specimen $(g)$.

2.4. Mercury Intrusion Porosimetry (MIP). MIP is a widely used method for measuring the pore size distribution of cement-based materials. In the MIP test, samples are intruded into a chamber; after the chamber is evacuated, the samples are surrounded by mercury, and the pressure ranges from subambient to $60,000 \mathrm{psi}(414 \mathrm{MPa})$. The contact angle and surface tension of mercury were assumed to be $117^{\circ}$ 
TABLE 2: Mix proportion and workability of mortar.

\begin{tabular}{|c|c|c|c|c|c|c|c|}
\hline \multicolumn{4}{|c|}{ Manufactured sand } & \multicolumn{4}{|c|}{ Natural sand } \\
\hline No. & $W / C$ & $S / C$ & Fluidity $(\mathrm{mm})$ & No. & $W / C$ & $S / C$ & Fluidity (mm) \\
\hline M1 & 0.4 & 1.0 & 257.0 & N1 & 0.4 & 1.0 & 267.5 \\
\hline M2 & 0.4 & 1.5 & 215.5 & N2 & 0.4 & 1.5 & 250.0 \\
\hline M3 & 0.4 & 2.0 & 162.0 & N3 & 0.4 & 2.0 & 197.5 \\
\hline M4 & 0.5 & 2.0 & 258.0 & N4 & 0.5 & 2.0 & 262.5 \\
\hline M5 & 0.5 & 2.5 & 187.0 & N5 & 0.5 & 2.5 & 227.5 \\
\hline M6 & 0.5 & 3.0 & 150.5 & N6 & 0.5 & 3.0 & 180.0 \\
\hline M7 & 0.6 & 2.5 & 265.5 & N7 & 0.6 & 2.5 & 280.0 \\
\hline M8 & 0.6 & 3.0 & 237.0 & N8 & 0.6 & 3.0 & 250.0 \\
\hline M9 & 0.6 & 3.5 & 150.5 & N9 & 0.6 & 3.5 & 212.5 \\
\hline M10 & 0.7 & 3.0 & 267.0 & N10 & 0.7 & 3.0 & 287.5 \\
\hline M11 & 0.7 & 3.5 & 242.0 & N11 & 0.7 & 3.5 & 265.0 \\
\hline M12 & 0.7 & 4.0 & 178.0 & N12 & 0.7 & 4.0 & 235.0 \\
\hline
\end{tabular}

TABLE 3: Parameters of pore structure of cement mortar.

\begin{tabular}{lccccccc}
\hline No. & Porosity $(\%)$ & Threshold radius $(\mathrm{nm})$ & Probable pore size $(\mathrm{nm})$ & No. & Porosity $(\%)$ & Threshold radius $(\mathrm{nm})$ & Probable pore size $(\mathrm{nm})$ \\
\hline M1 & 22.30 & 202.3 & 66.7 & N1 & 20.99 & 228.1 & 82.29 \\
M2 & 20.03 & 246.2 & 67.2 & N2 & 19.13 & 242.9 & 79.56 \\
M3 & 18.48 & 186.5 & 65.8 & N3 & 16.00 & 242.9 & 90.07 \\
M4 & 22.23 & 216.5 & 77.0 & N4 & 19.55 & 561.8 & 90.07 \\
M5 & 21.30 & 220.9 & 78.7 & N5 & 17.97 & 1089.0 & 88.75 \\
M6 & 19.09 & 246.2 & 81.1 & N6 & 17.64 & 561.8 & 92.32 \\
M7 & 22.53 & 150.1 & 86.1 & N7 & 19.91 & 562.1 & 103.2 \\
M8 & 20.51 & 160.0 & 89.8 & N8 & 18.93 & 562.1 & 107.8 \\
M9 & 21.26 & 182.7 & 92.8 & N9 & 18.90 & 562.1 & 97.0 \\
M10 & 23.87 & 491.5 & 95.2 & N10 & 20.09 & 959.1 & 97.0 \\
M11 & 22.22 & 504.3 & 96.5 & N11 & 20.50 & 959.1 & 93.11 \\
M12 & 21.60 & 574.4 & 98.2 & N12 & 19.58 & 1015.0 & 9 \\
\hline
\end{tabular}

and $0.484 \mathrm{~N} / \mathrm{m}$, respectively. On the pressure, the smallest pore size into which mercury can be intruded is $2 \mathrm{~nm}$ and the largest pore size which can be intruded is $200 \mathrm{~mm}$ with subambient pressure [25]. The MIP results are obtained in the form of raw data representing cumulative intruded volume versus pore diameter curves and logarithmic differential intruded volume versus pore diameter of cement mortar curves.

\section{Pore Size Distribution of Cement Mortar}

\subsection{Test Results}

3.1.1. Manufactured Sand Mortar. In this section, the pore structure of manufactured sand mortars with different mix proportions after 28 days of curing is discussed. The cumulative intrusion versus pore diameter curves and differential curves is shown in Figures 2 and 3, respectively. And detailed pore structure parameters are listed in Table 3.

The MIP test data indicate a threshold radius below which there is relatively little intrusion and immediately above where rapid intrusion commences. This corresponds to the region of inflection, following an almost horizontal portion of cumulative intrusion curves. The test results also indicate that the threshold radius increases with increasing fine aggregate and water to cement ratio. If the threshold radius is assumed to be the initial intergranular spacing at the setting time, the higher water to cement ratio generates a higher threshold radius. As aggregate volume concentration increases, the threshold region tends to flatten out and the threshold radius increases $(228 \mathrm{~nm}-1015 \mathrm{~nm})$ progressively, which can be attributed to the fine aggregate effect of the reorientation of the pore system of mortar. Different from cement paste, the threshold radius in the mortar is linked to the binder-aggregate interface or even fissures rather than to the pores alone [26]. Feldman [27] demonstrated that the total intruded pore volume decreased with increasing aggregate volume concentration. However, intruded pore volume per volume of paste in the mortar increases with increasing aggregate volume concentration. This strongly suggested that pores being intruded by mercury may not be pores in the paste alone but could include fissures and bond cracks at the aggregate-paste interface. 


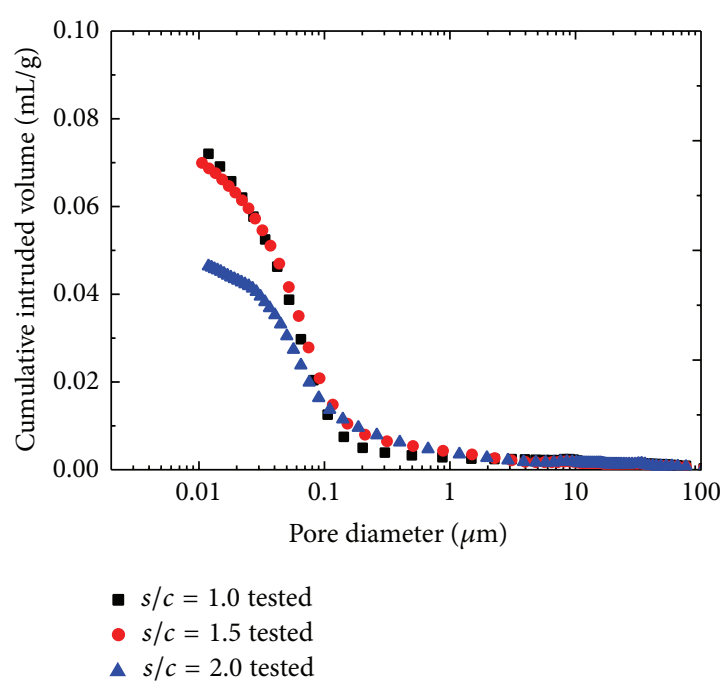

(a) $w / c=0.4$

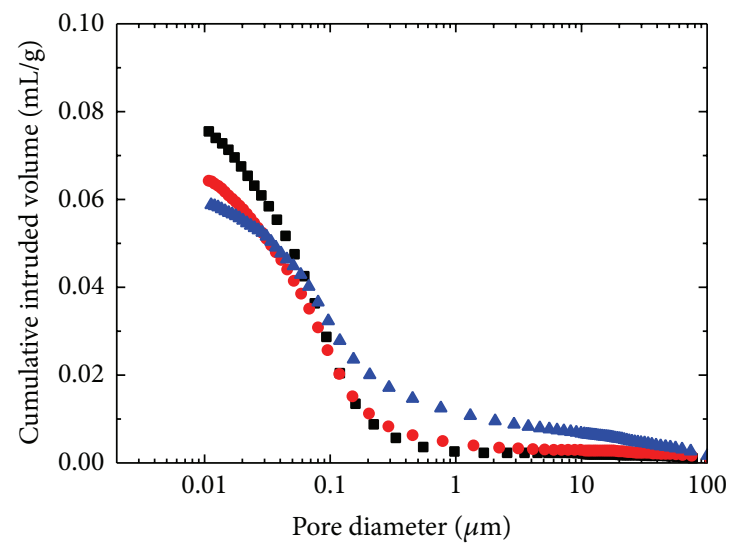

- $s / c=2.5$ tested

- $s / c=3.0$ tested

$\Delta s / c=3.5$ tested

(c) $w / c=0.6$

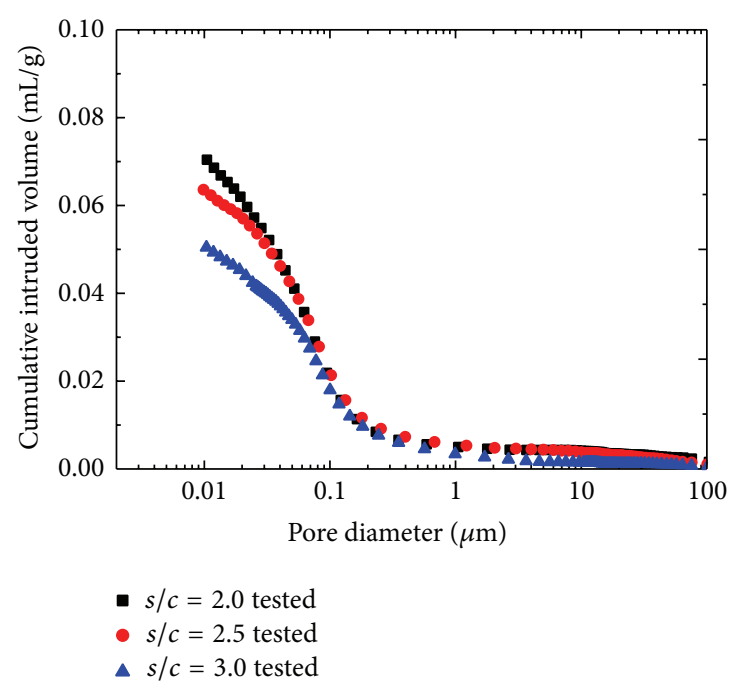

(b) $w / c=0.5$

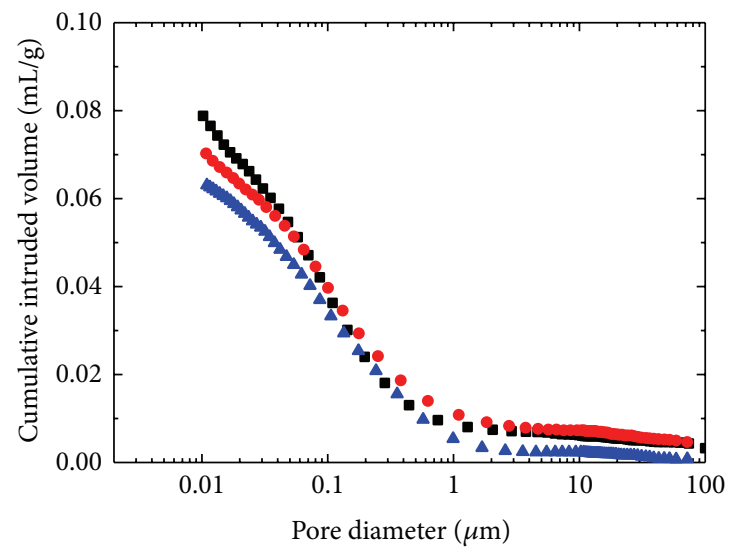

- $s / c=3.0$ tested
- $s / c=3.5$ tested
- $s / c=4.0$ tested

(d) $w / c=0.7$

FIGURE 2: Cumulative intruded pore volume versus pore diameter for MS mortars.

It can be found in Figure 3 that the character of pore size distribution curves of manufactured sand mortars is influenced by both $w / c$ and $s / c$. The difference in pore structure between cement mortar of different $w / c$ lies mainly in the region of large pores; mortar with higher $w / c$ has a group of larger pores. This is consistent with experimental research from Gonçalves et al. [28]. Differential curves for mortars with lower $w / c$ exhibit a sharply defined initial peak indicating a unimodal distribution of pore sizes. As $w / c$ increases, a second more rounded peak appears at a larger pore size, thus presenting a bimodal distribution. The presence of a sharply defined intrusion peak in the differential curve indicates the intrusion of mercury throughout a pore network connected to the specimen surface $[29,30]$. Therefore, the initial intrusion peak observed here corresponds to the minimum throat dimension of an interconnected capillary network. The rounded peak appears in the pore size of above $10 \mathrm{~mm}$, which is probably favored in large aggregate volume concentration and $w / c$. The most probable pore size corresponding to initial peak ranges from $65 \mathrm{~nm}$ to $100 \mathrm{~nm}$ in MS mortars and increases with both the increment of fine aggregate and $w / c$ ratio.

3.1.2. Natural Sand Mortar. The cumulative intrusion versus pore diameter curves and differential curves of natural sand mortar is shown in Figures 4 and 5, respectively. And detailed pore structure parameters are listed in Table 4.

It can be found from the test results that the influence of $w / c$ and $s / c$ on characteristics of the pore structure of the natural sand mortar is similar to the manufactured sand mortar. The total porosity of the manufactured sand mortar is higher, which is ascribed to the angular shape and rough texture of manufactured sand $[2,31]$. However, due to 

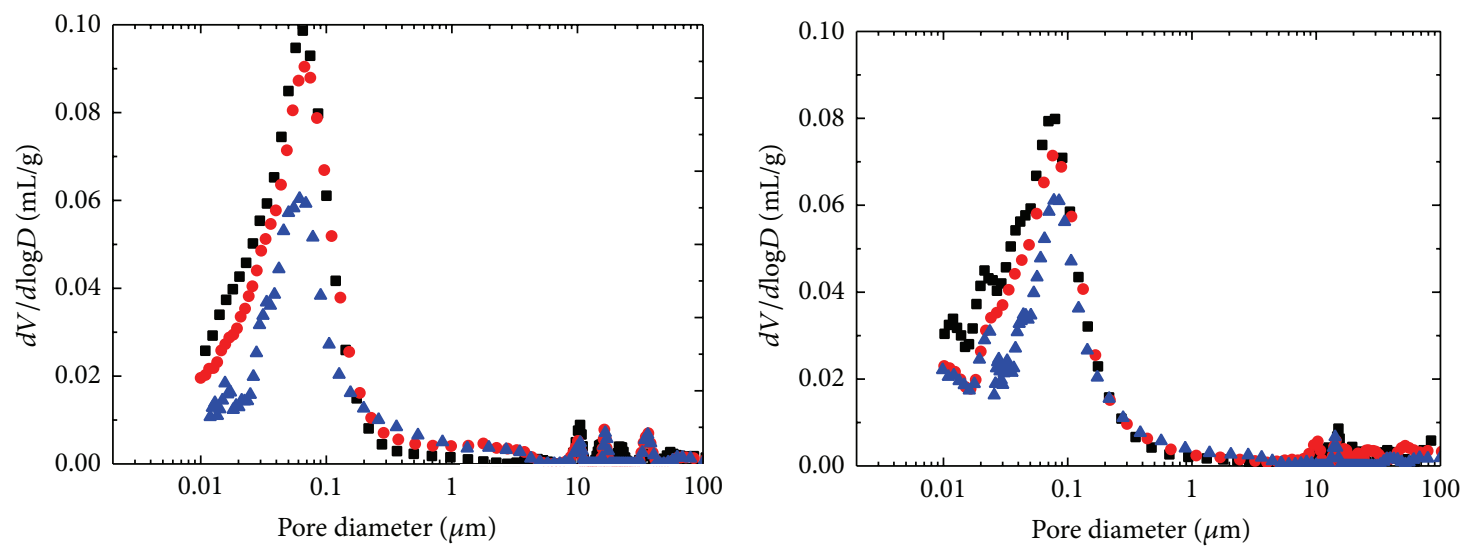

- $s / c=1.0$ tested

- $s / c=1.5$ tested

- $s / c=2.0$ tested

- $s / c=2.5$ tested

$\Delta s / c=2.0$ tested

$\Delta / c=3.0$ tested

(a) $w / c=0.4$

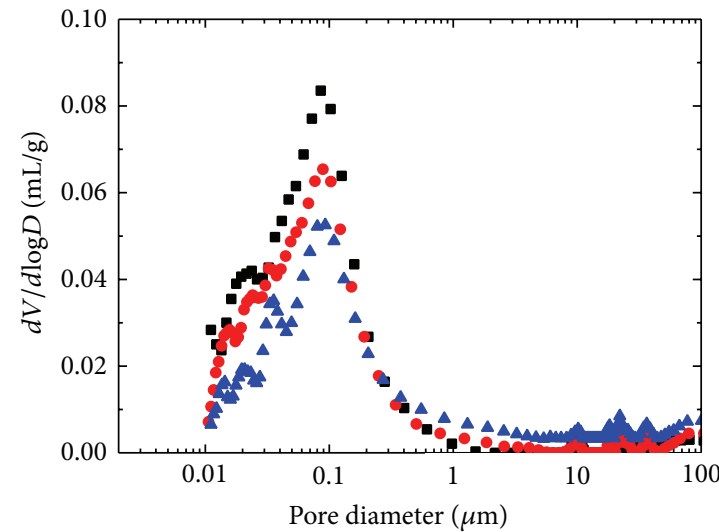

(b) $w / c=0.5$

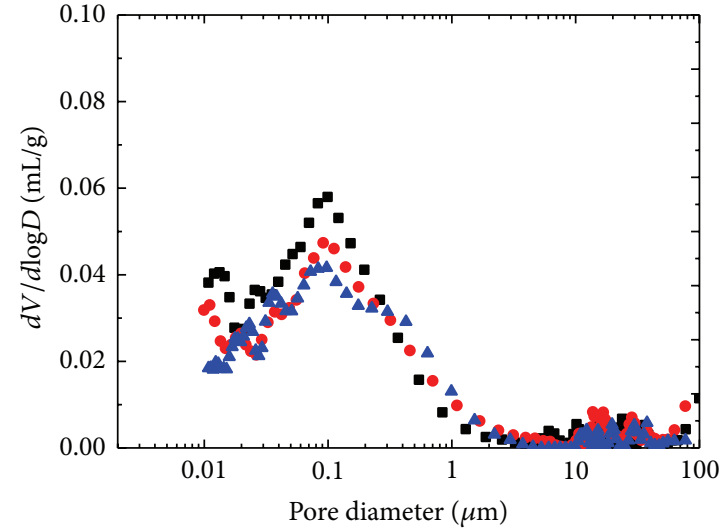

- $s / c=2.5$ tested

- $s / c=3.0$ tested

- $s / c=3.0$ tested

- $s / c=3.5$ tested

- $s / c=4.0$ tested

(c) $w / c=0.6$

(d) $w / c=0.7$

FIGURE 3: Differential intrudes volume versus pore diameter for MS mortars.

TABLE 4: Pore size distribution models of cement-based materials.

\begin{tabular}{lc}
\hline Models & Equations \\
\hline $\begin{array}{l}\text { Diamond and Dolch } \\
\text { model [18] }\end{array}$ & $f(d)=\frac{1}{\sqrt{2 \pi} \ln \sigma} \exp \left[-\left(\frac{\ln \left(d^{*}\right) / \bar{d}^{*}}{\sqrt{2} \ln \sigma}\right)^{2}\right]$ \\
\hline $\begin{array}{l}\text { Van Breugel model [19] } \\
V_{(\leq d)}=a \cdot\left[\ln \left(\frac{d}{d_{0}}\right)\right]^{n}\end{array}$ & $a, n$ \\
\hline $\begin{array}{l}\text { Shi and Brown model } \\
\text { [20] }\end{array}$ & $p(x)=\frac{1}{\sqrt{2 \pi \sigma^{2} x}} \exp \left[-\frac{1}{2}\left(\frac{\log (x)-\mu}{2}\right)^{2}\right]$ \\
$\begin{array}{l}\text { Shimomurat and } \\
\text { Maekawa model [21] }\end{array}$ & $p(x)=\sum f_{i} p\left(x, \mu_{i}, \sigma_{i}\right), \quad \sum f_{i}=1$ \\
\hline $\begin{array}{l}\text { Patil and Bhattacharjee } \\
\text { model [22] }\end{array}$ & $V_{(d)}=V_{0}\left[1-\exp \left(-B d^{C}\right)\right]$ \\
\hline
\end{tabular}



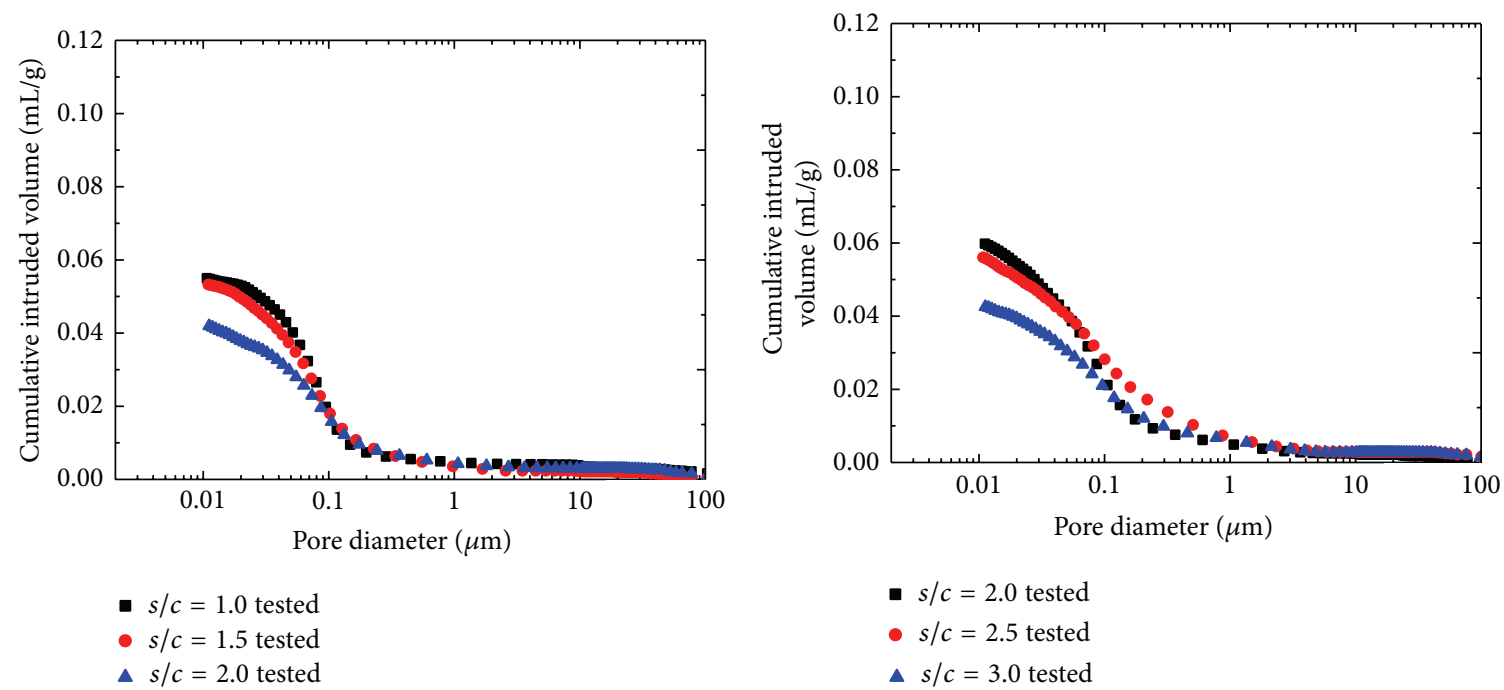

(a) $w / c=0.4$

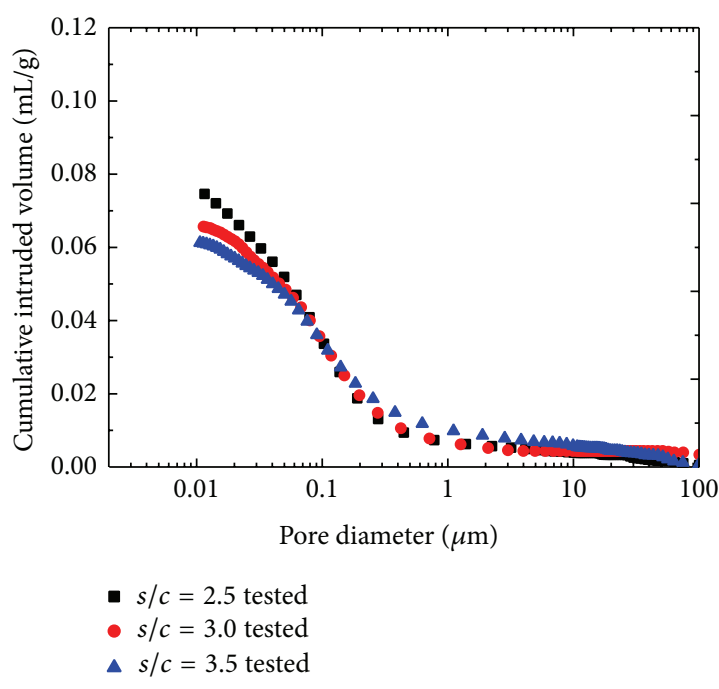

(c) $w / c=0.6$ (b) $w / c=0.5$

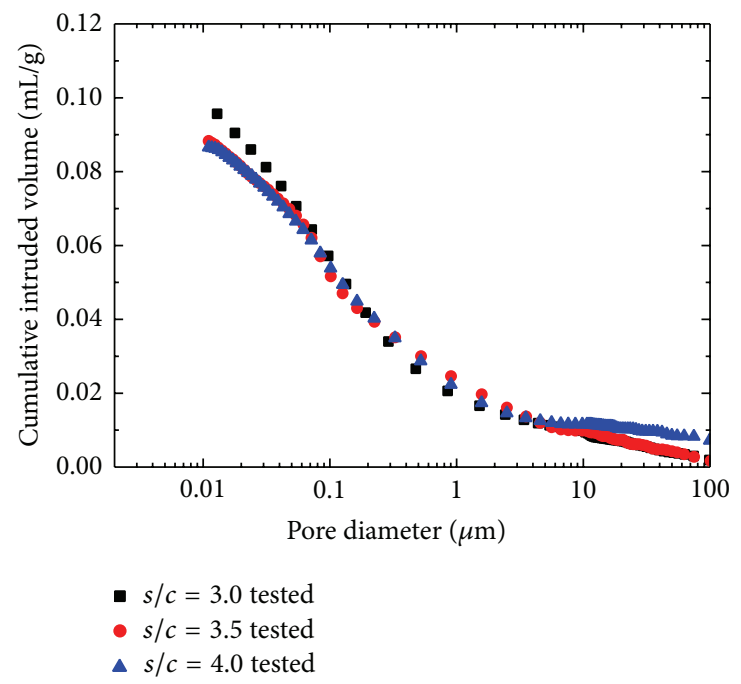

(d) $w / c=0.7$

FIGURE 4: Cumulative intruded pore volume versus pore diameter for NS mortars.

its better particle size distribution, the manufactured sand mortar has finer threshold radius and probable pore size natural sand mortar.

\subsection{Comparison Test Results with Existing Models. An appro-} priate pore size distribution model of cement-based materials determined by MIP should be one that not only fits the experimental data but also has the reasonable physical meaning of pore structure. Historically, several general types of models have been proposed for pore size distribution of cement-based materials [18-22], as shown in Table 4.

In this experimental research, the fit of existing models of distribution functions was examined for three mix proportions at $w / c=0.5$ cement mortars of varying $s / c$ prepared with manufactured sand and natural sand as the representatives, as shown in Figures 6 and 7, respectively.
By comparison to experiments, as shown in Figures 6(a) and 7(a), if both fine and coarse pores are included in cement mortar, a single lognormal distribution model is not adequate. Figures 6(c) and 7(c) show that the Van Breugel model has poor precision. The simulated distribution is coarser than those obtained by the MIP test when the pore size is coarser than $0.1 \mathrm{~mm}$, which is the simulation overestimating the volume of larger pores. This may be related to the real world flocculation of cement particles, which is not included in the Van Breugel model.

Compound lognormal distribution is excellent to simulate the pore size distribution by MIP test, as shown in Figures 6(b) and 7(b); $2 \mathrm{~nm}$ to about $0.2 \mathrm{~mm}$ have been included in this compound lognormal model. The first subdistribution is associated with coarse pores that may extend to voids. The third subdistribution is associated with fine pores that may extend to gel pores. The middle distribution includes capillary 

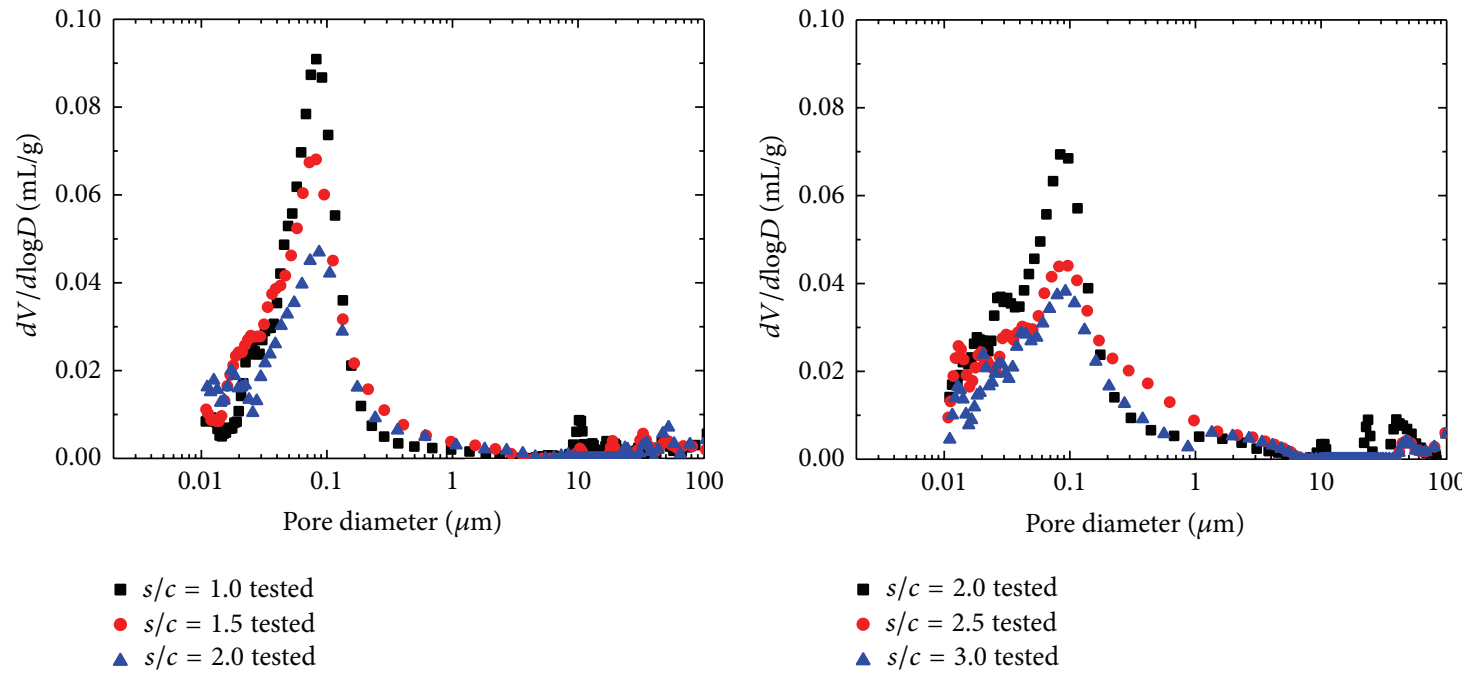

(a) $w / c=0.4$
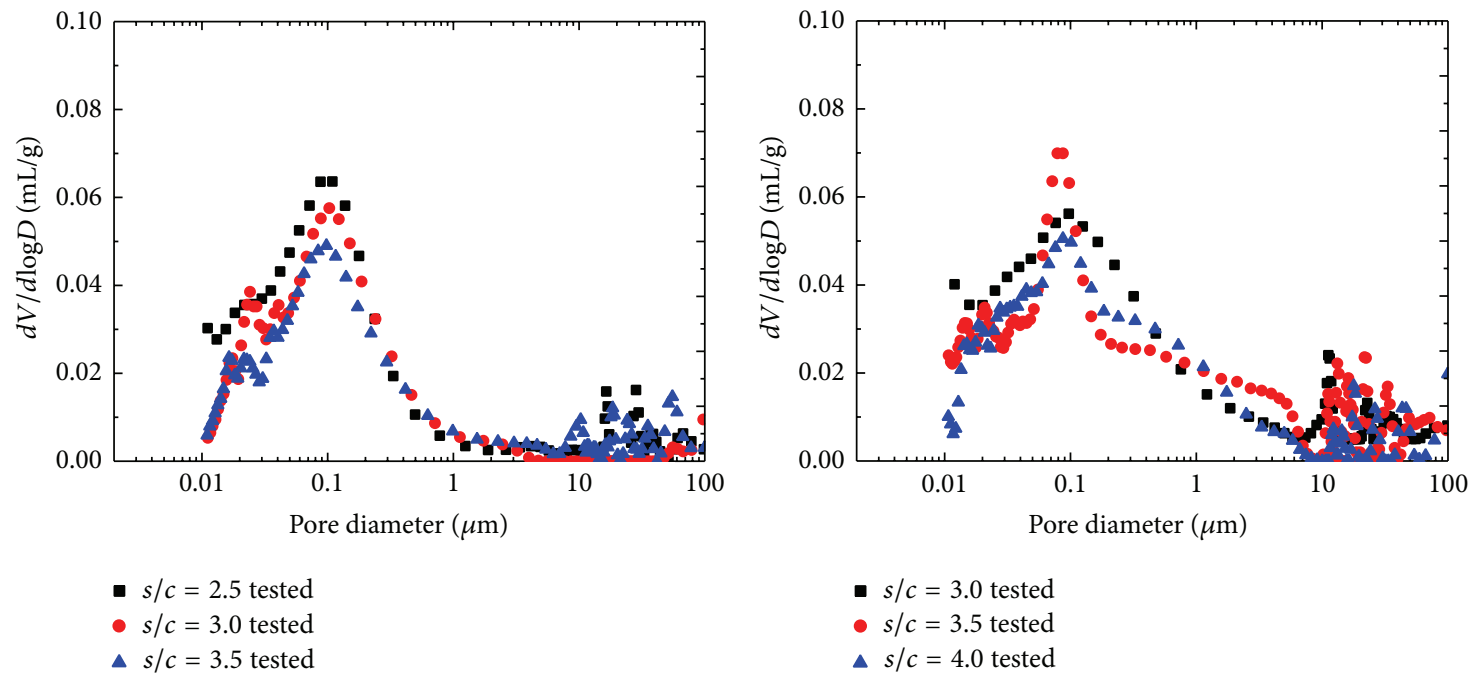

(c) $w / c=0.6$

(d) $w / c=0.7$

FIGURE 5: Differential intrudes volume versus pore diameter for NS mortars.

pores. Shimomura and Maekawa and Patil and Bhattacharjee models have both directly given the relationship between the cumulative intruded volume and pore diameter. The simulated results and experimental data by MIP showed a good correlation.

\section{Strength-Pore Structure Relationship}

4.1. Porosity. Taking an empirical approach, connections between the porosity and strength of solid materials have been established by many researchers [8-11]. Based on these models, the relationship between strength and porosity of cement mortar had been given by Chen et al. [12]; meanwhile, a model to predict strength was proposed. The simulated results have shown that the extended Zheng's model is a good representation of the experimental data on the strength of cement mortar. In this paper, experimental results show that strength and porosity have obvious discreteness, as shown in Figure 8, which results in the existing models being unavailable to simulate the relationship between strength and porosity of cement mortar.

4.2. Pore Structure. In traditional researches, porosity is the only influential factor on the strength of cement-based materials taken into consideration, which is empirical or semiempirical. This experimental data results in these existing models being unavailable to simulate the relationship between strength and porosity of cement mortar. Therefore, other pore structure parameters such as mean diameter should be taken into account. Cumulative intruded volume versus pore diameter curve is divided into $n$ shares averagely 


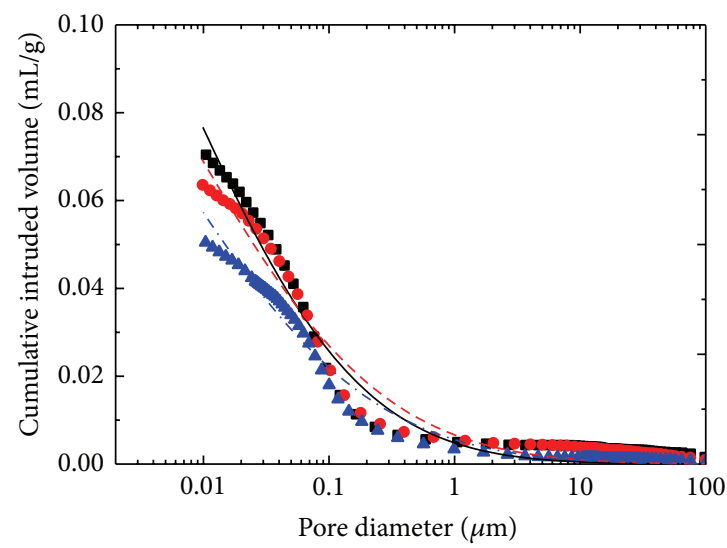

(a) Diamond and Dolch model

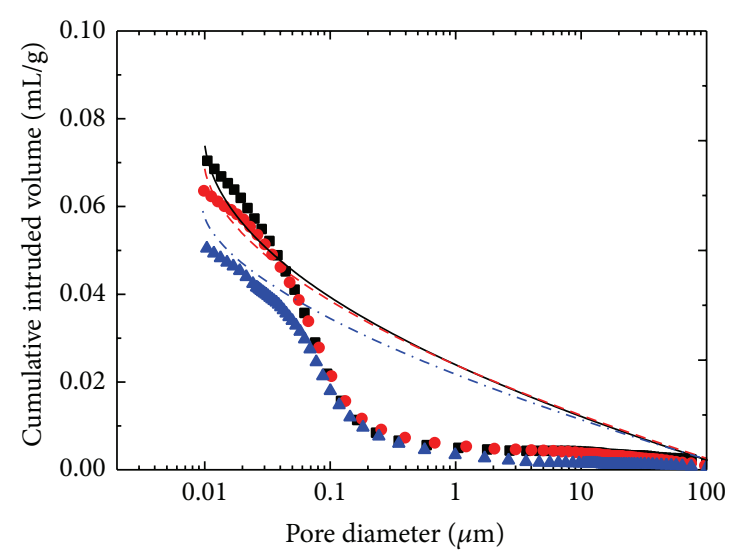

(c) Van Breugel model

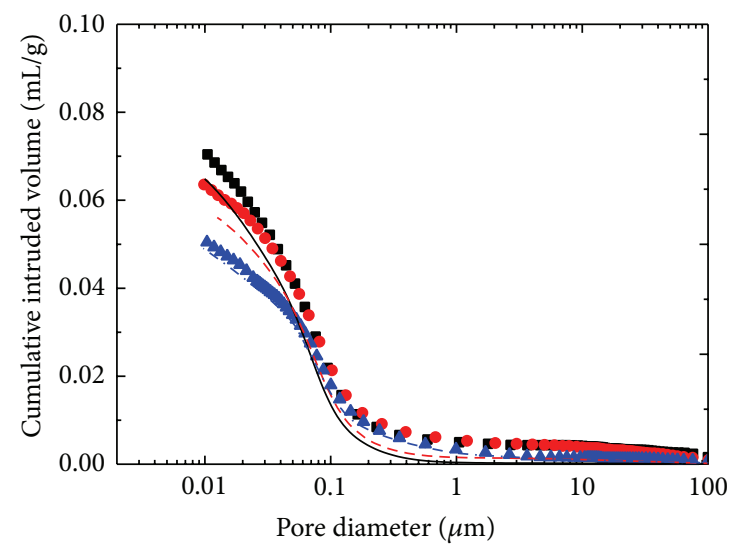

(b) Shi and Brown model

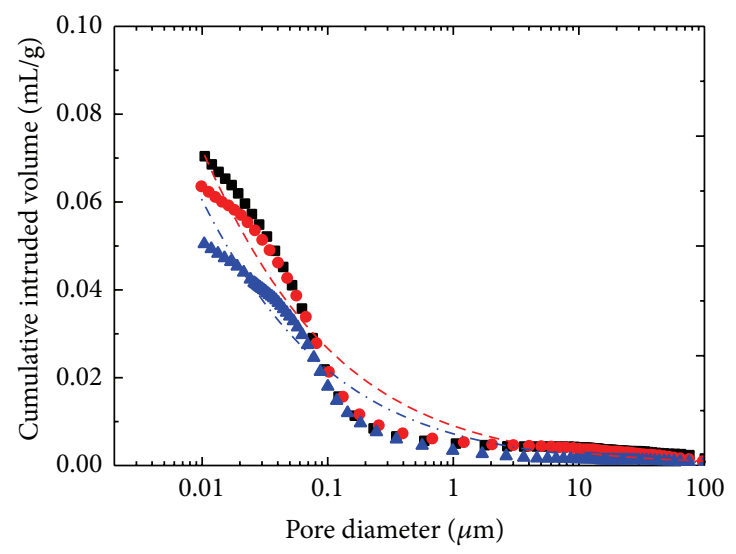

(d) Shimomura and Maekawa model

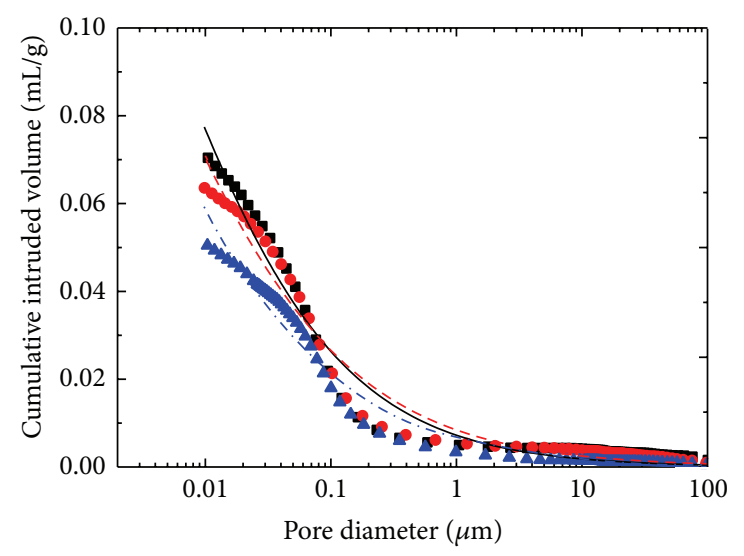

- $s / c=2.0$ tested $\quad--s / c=2.5$ predicted

$-s / c=2.0$ predicted $\quad \Delta \quad s / c=3.0$ tested

- $s / c=2.5$ tested $\quad .--s / c=3.0$ predicted

(e) Patil and Bhattacharjee model

FIGURE 6: Comparison between test and predicted results by existing models for manufactured sand mortar. 


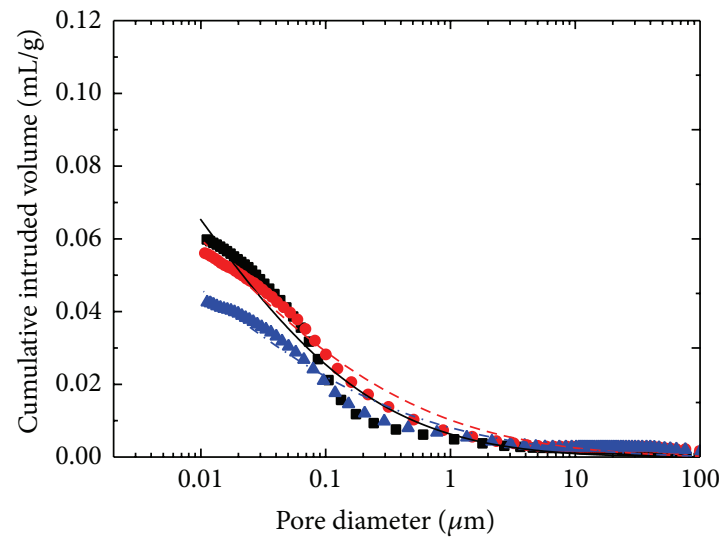

(a) Diamond and Dolch model

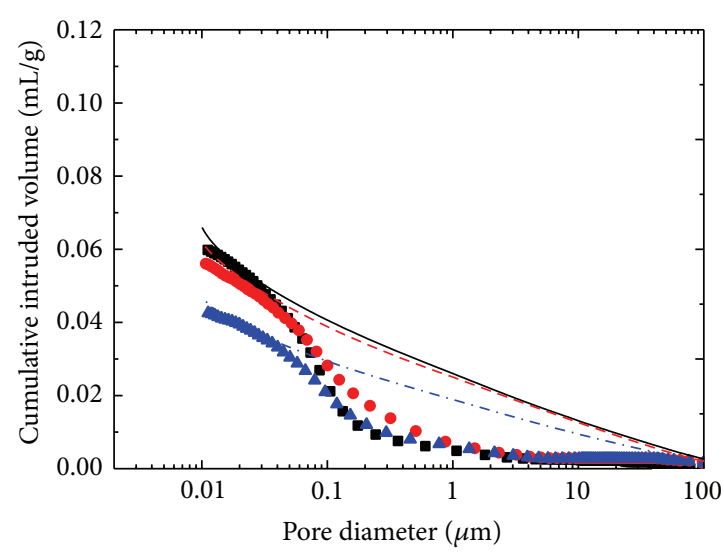

(c) Van Breugel model

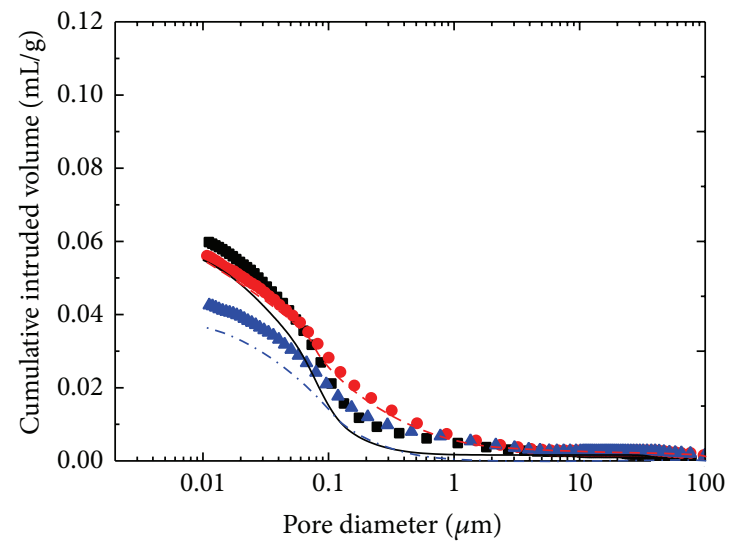

(b) Shi and Brown model

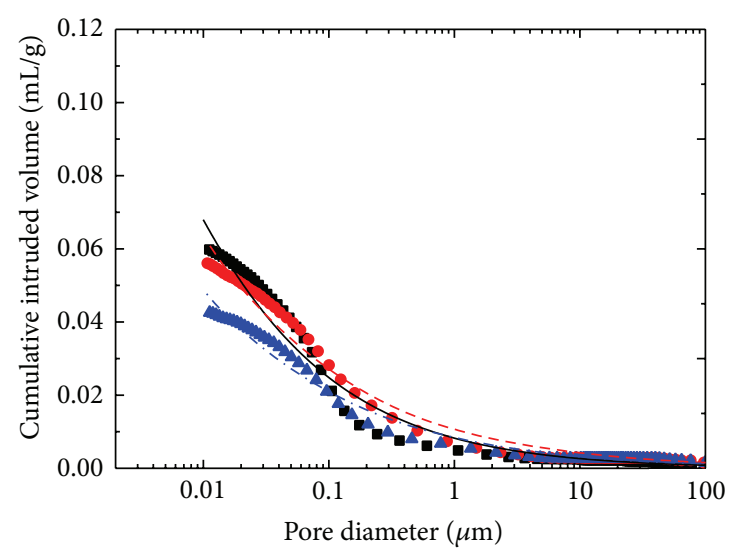

(d) Shimomura and Maekawa model

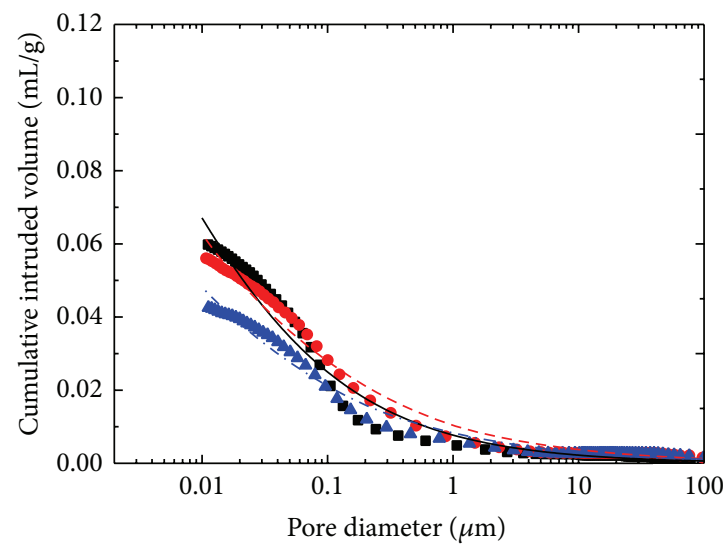

$\begin{aligned}-s / c & =2.0 \text { tested } \quad---s / c=2.5 \text { predicted } \\ -s / c & =2.0 \text { predicted } \quad \Delta \quad s / c=3.0 \text { tested } \\ -s / c & =2.5 \text { tested } \quad--s / c=3.0 \text { predicted }\end{aligned}$

(e) Patil and Bhattacharjee model

FIGURE 7: Comparison between test and predicted results by existing models for natural sand mortar. 


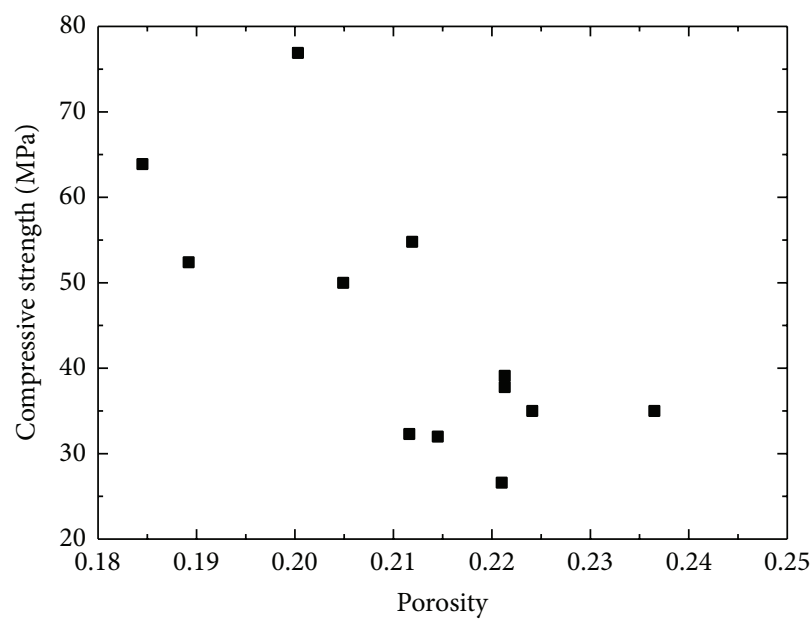

- Tested data

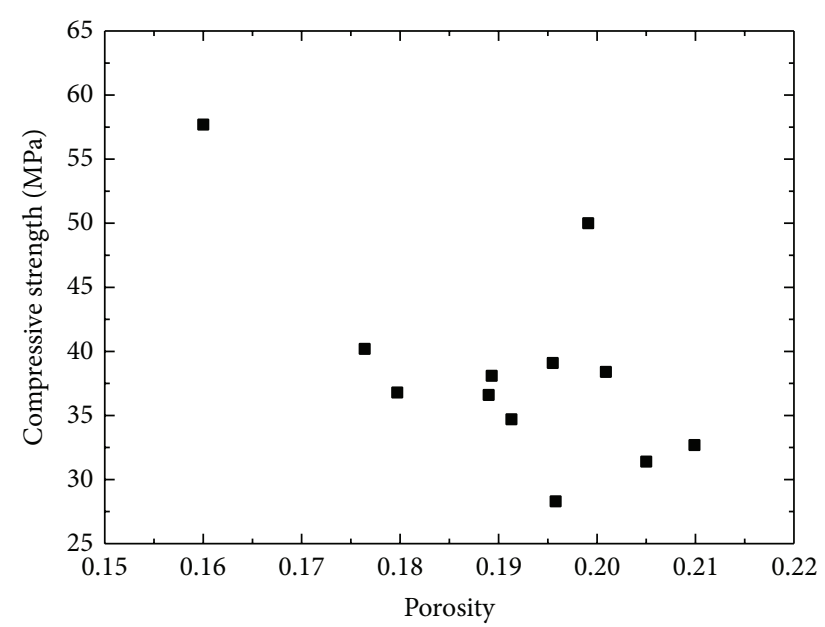

- Tested data

(a)

(b)

FIGURE 8: Compressive strength versus porosity of cement mortar: (a) manufactured sand and (b) natural sand.

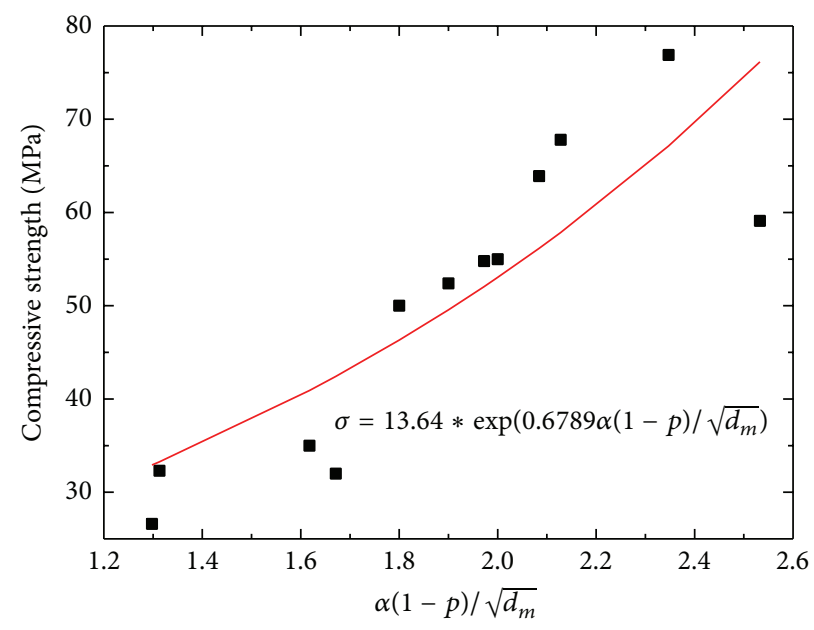

- Tested

Predicted $R^{2}=0.7276$

(a)

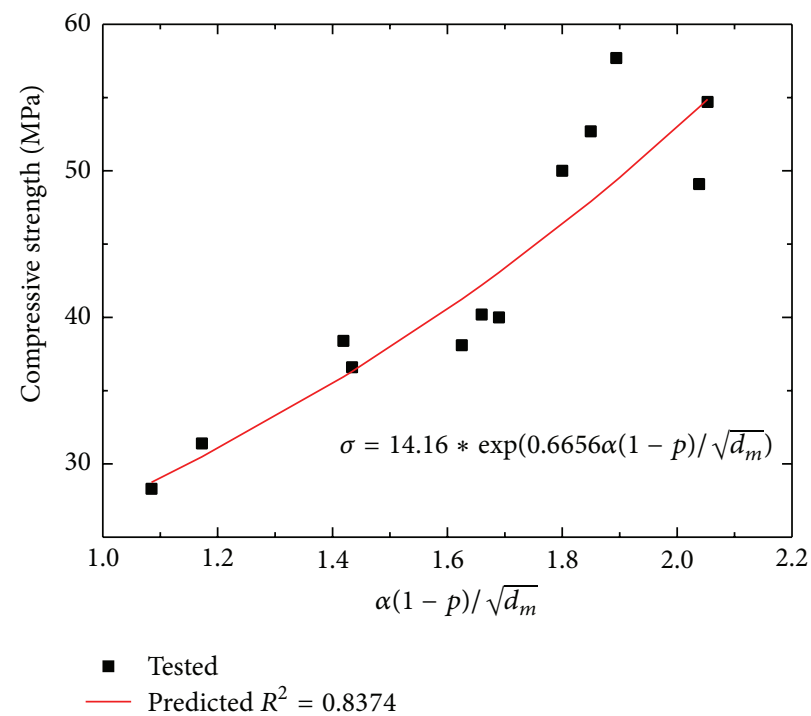

(b)

FIGURE 9: Relationship between experimental results of compressive strength and model formula $\alpha(1-p) / \sqrt{d_{m}}$ : (a) manufactured sand mortar and (b) natural sand mortar.

and $V_{i}$ represents the volume of pore diameter $d_{i}$. The mean diameter can be calculated as follows:

$$
\ln d_{m}=\frac{\sum_{i=1}^{i=n} V_{i} \ln d_{i}}{\sum_{i=1}^{i=n} V_{i}}
$$

where $d_{m}$ is the mean diameter and $d_{i}$ is the $i$ th pore diameter.
The mean diameter $d_{m}$ is considered to account for the influence of pore structure on the compressive strength of concrete:

$$
\sigma=K C \frac{(1-P)}{\sqrt{d_{m}}},
$$

where $d_{m}$ is mean diameter, $P$ is the total porosity, $C$ is cement content, and $K$ is parameter. 
Kondraivendhan and Bhattacharjee [32] have proposed a relationship between compressive strength and hydration degree, mean diameter, and porosity as follows:

$$
\sigma=K C \alpha \frac{(1-P)}{\sqrt{d_{m}}},
$$

where $K$ is empirical parameter, $C$ is cement content, and $\alpha$ is hydration degree.

In this paper, an extended Bhattacharjee model is proposed as follows:

$$
\sigma=K \exp \left(B \alpha \frac{(1-P)}{\sqrt{d_{m}}}\right)
$$

where $K$ and $B$ are experimental parameters.

Figure 9 shows the relationship between compressive strength and $\alpha(1-P) / \sqrt{d_{m}}$. Porosity, mean diameter, and hydration degree are taken into consideration, which clearly explain the relationship between pore structure and strength of cement mortar.

\section{Conclusions}

(1) Porosity of manufactured sand mortar is higher than that of natural sand mortar, and the compressive strength is higher than that of natural sand mortar, which demonstrates that porosity is not the only influential factor on compressive strength of mortar. The probable pore size and threshold radius of manufactured sand mortar are finer. Besides, the probable pore size and threshold radius increase with increasing water to cement ratio and sand to cement ratio.

(2) The existing models of pore size distribution of cement-based materials have been reviewed and compared with test results in this investigation. A single lognormal distribution may not be adequate if both fine and coarse pores are included in cement mortar. Although too many parameters are included in the model, the compound lognormal distribution is excellent to simulate the experimental pore size distributions. The Van Breugel model has poor precision. Shimomura and Patil models are similar, and the parameter is simple and particular with $w / c$ and $s / c$ and so on.

(3) The extended Bhattacharjee model was built to examine the relationship between compressive strength and pore structure. Porosity, mean diameter, and hydration degree were taken into consideration, which clearly explain the relationship between pore structure and strength of cement mortar.

\section{Conflict of Interests}

The authors declare that there is no conflict of interests regarding the publication of this paper.

\section{Acknowledgments}

The authors gratefully acknowledge the support of the National Natural Science Foundation of China (Grant nos. 51309090 and 51108231), the National Science Foundation for Postdoctoral Scientists of China (Grant no. 2013M531268), and Jiangsu Planned Projects for Postdoctoral Research Funds (Grant no. 1302101C).

\section{References}

[1] M. R. Wakchaure and E. G. BE, "Effect of types of fine aggregate on mechanical properties of cement concrete," International Journal of Modern Engineering Research, vol. 2, pp. 3723-3726, 2012.

[2] B. Li, G. Ke, and M. Zhou, "Influence of manufactured sand characteristics on strength and abrasion resistance of pavement cement concrete," Construction and Building Materials, vol. 25, no. 10, pp. 3849-3853, 2011.

[3] P. Nanthagopalan and M. Santhanam, "Fresh and hardened properties of self-compacting concrete produced with manufactured sand," Cement and Concrete Composites, vol. 33, no. 3, pp. 353-358, 2011.

[4] V. Bhikshma, R. Kishore, and C. V. R. Pathi, "Investigations on flexural behavior of high strength manufactured sand concrete," 2010.

[5] S. Diamond, "A critical comparison of mercury porosimetry and capillary condensation pore size distributions of portland cement pastes," Cement and Concrete Research, vol. 1, no. 5, pp. 531-545, 1971.

[6] I. Odler and M. Rößler, "Investigations on the relationship between porosity, structure and strength of hydrated Portland cement pastes. II. Effect of pore structure and of degree of hydration," Cement and Concrete Research, vol.15, no. 3, pp. 401410, 1985

[7] R. Kumar and B. Bhattacharjee, "Porosity, pore size distribution and in situ strength of concrete," Cement and Concrete Research, vol. 33, no. 1, pp. 155-164, 2003.

[8] M. Y. Balshin, "Relation of mechanical properties of powder metals and their porosity and the ultimate properties of porousmetal ceramic materials," Doklady Akademii Nauk SSSR, vol. 67, no. 5, pp. 831-834, 1949.

[9] R. Ryshkevitch, "Compression strength of porous sintered alumina and zirconia," Journal of American Ceramic Society, vol. 36, no. 2, pp. 65-68, 1953.

[10] K. K. Schiller, "Strength of porous materials," Cement and Concrete Research, vol. 1, no. 4, pp. 419-422, 1971.

[11] D. P. H. Hasselman, "Griffith flaws and the effect of porosity on tensile strength of brittle ceramics," Journal of American Ceramic Society, vol. 52, no. 8, p. 457, 1969.

[12] X. D. Chen, S. X. Wu, and J. K. Zhou, "Influence of porosity on compressive and tensile strength of cement mortar," Construction and Building Materials, vol. 40, pp. 869-874, 2013.

[13] S. Mindess, J. F. Young, and D. Darwin, Concrete, Prentice Hall, Englewood Cliffs, NJ, USA, 1981.

[14] C. C. Yang, S. W. Cho, and L. C. Wang, "The relationship between pore structure and chloride diffusivity from ponding test in cement-based materials," Materials Chemistry and Physics, vol. 100, no. 2-3, pp. 203-210, 2006.

[15] L. Tang and L.-O. Nilsson, "A new approach to the determination of pore distribution by penetrating chlorides into concrete," Cement and Concrete Research, vol. 25, no. 4, pp. 695-701, 1995. 
[16] J. Yu, J. C. Yu, M. K.-P. Leung et al., "Effects of acidic and basic hydrolysis catalysts on the photocatalytic activity and microstructures of bimodal mesoporous titania," Journal of Catalysis, vol. 217, no. 1, pp. 69-78, 2003.

[17] V. Cnudde, A. Cwirzen, B. Masschaele, and P. J. S. Jacobs, "Porosity and microstructure characterization of building stones and concretes," Engineering Geology, vol. 103, no. 3-4, pp. 76-83, 2009.

[18] S. Diamond and W. L. Dolch, "Generalized log-normal distribution of pore sizes in hydrated cement paste," Journal of Colloid and Interface Science, vol. 38, no. 1, pp. 234-244, 1972.

[19] K. van Breugel, "Numerical simulation of hydration and microstructural development in hardening cement-based materials (I) theory," Cement and Concrete Research, vol. 25, no. 2, pp. 319-331, 1995.

[20] D. X. Shi and P. W. Brown, "Lognormal simulation of pore size distributions in cementations materials," Journal of American Ceramic Society, vol. 74, no. 8, pp. 1861-1867, 1991.

[21] T. Shimomurat and K. Maekawa, "Analysis of the drying shrinkage behaviour of concrete using a micromechanical model based on the micropore structure of concrete," Magazine of Concrete Research, vol. 49, no. 181, pp. 303-322, 1997.

[22] S. G. Patil and B. Bhattacharjee, "Size and volume relationship of pore for construction materials," Journal of Materials in Civil Engineering, vol. 20, no. 6, pp. 410-418, 2008.

[23] H. N. Atahan, O. N. Oktar, and M. A. Taşdemir, "Effects of water-cement ratio and curing time on the critical pore width of hardened cement paste," Construction and Building Materials, vol. 23, no. 3, pp. 1196-1200, 2009.

[24] D. Winslow and D. Liu, "The pore structure of paste in concrete," Cement and Concrete Research, vol. 20, no. 2, pp. 227-235, 1990.

[25] R. A. Cook and K. C. Hover, "Mercury porosimetry of hardened cement pastes," Cement and Concrete Research, vol. 29, no. 6, pp. 933-943, 1999.

[26] D. C. Okpala, "Pore structure of hardened cement paste and mortar," International Journal of Cement Composites and Lightweight Concrete, vol. 11, no. 4, pp. 245-254, 1989.

[27] R. F. Feldman, "The effect of sand/cement ratio and silica fume on the microstructure of mortars," Cement and Concrete Research, vol. 16, no. 1, pp. 31-39, 1986.

[28] J. P. Gonçalves, L. M. Tavares, R. D. Toledo Filho, E. M. R. Fairbairn, and E. R. Cunha, "Comparison of natural and manufactured fine aggregates in cement mortars," Cement and Concrete Research, vol. 37, no. 6, pp. 924-932, 2007.

[29] X. Chen and S. Wu, "Influence of water-to-cement ratio and curing period on pore structure of cement mortar," Construction and Building Materials, vol. 38, no. 6, pp. 804-812, 2013.

[30] E. J. Garboczi, "Permeability, diffusivity, and microstructural parameters: a critical review," Cement and Concrete Research, vol. 20, no. 4, pp. 591-601, 1990.

[31] K. A. Snyder, D. N. Winslow, D. P. Bants, and E. J. Garboczi, "Interfacial zone percolation cement-aggregate composites," in RILEM Proceedings, Toulouse, France, October 1992.

[32] B. Kondraivendhan and B. Bhattacharjee, "Effect of age and water-cement ratio on size and dispersion of pores in ordinary portland cement paste," ACI Materials Journal, vol. 107, no. 2, pp. 147-154, 2010. 

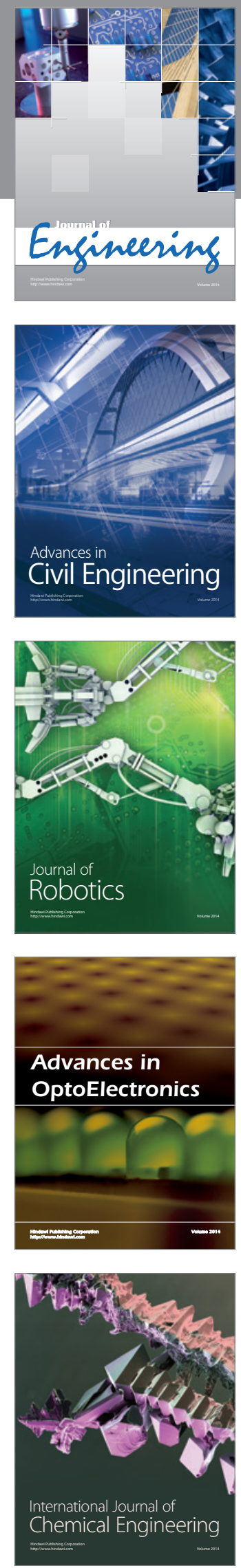

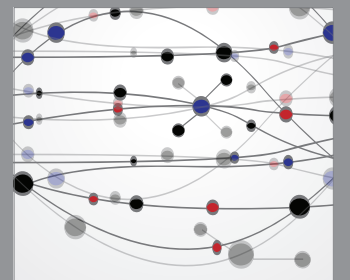

The Scientific World Journal
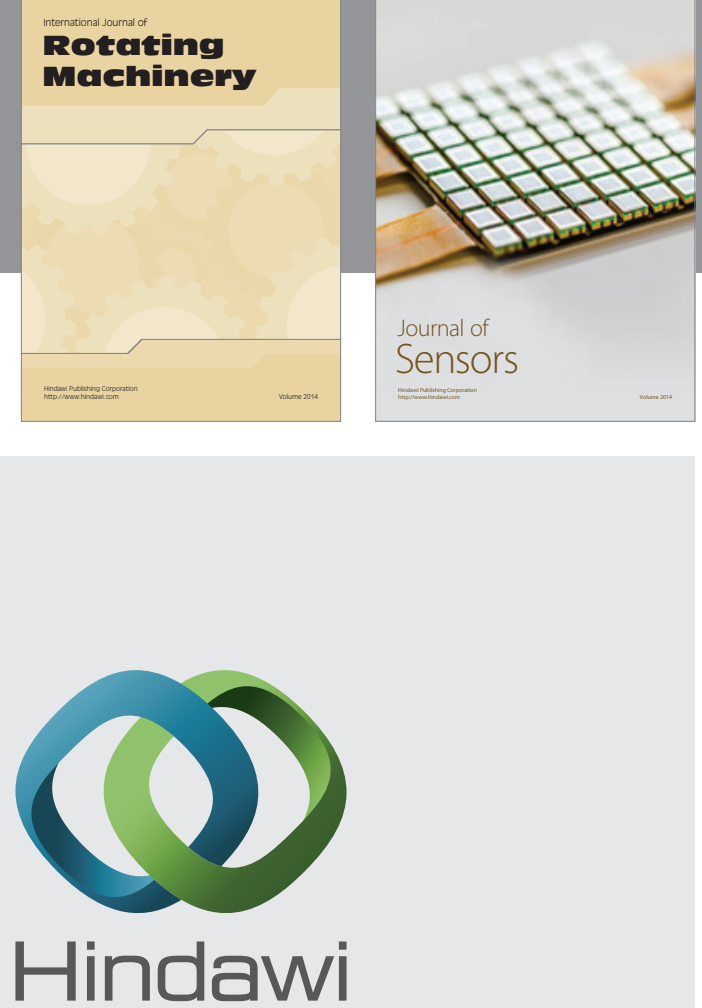

Submit your manuscripts at http://www.hindawi.com
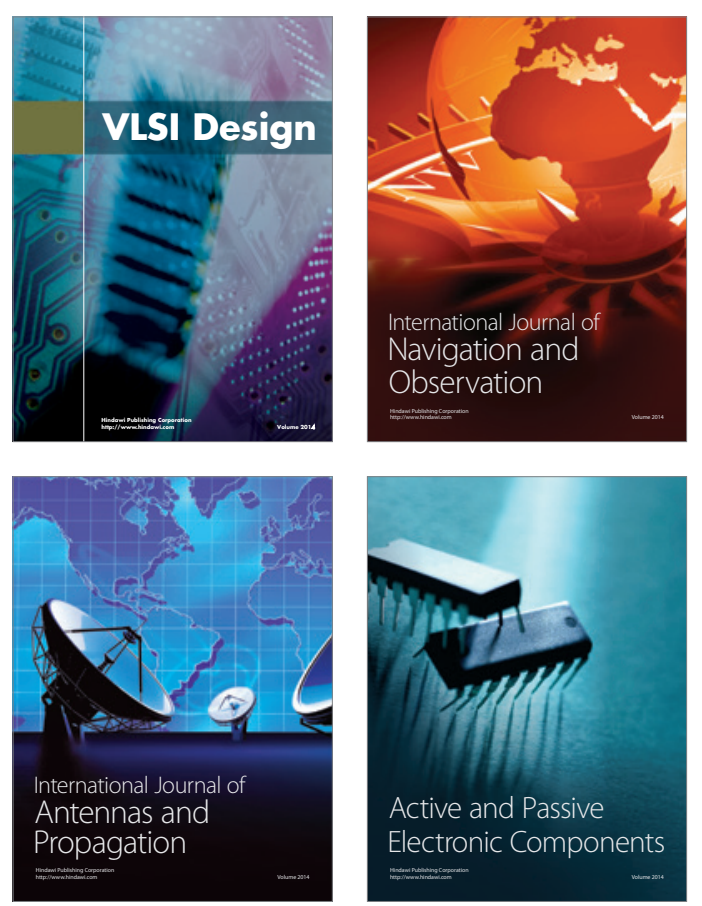
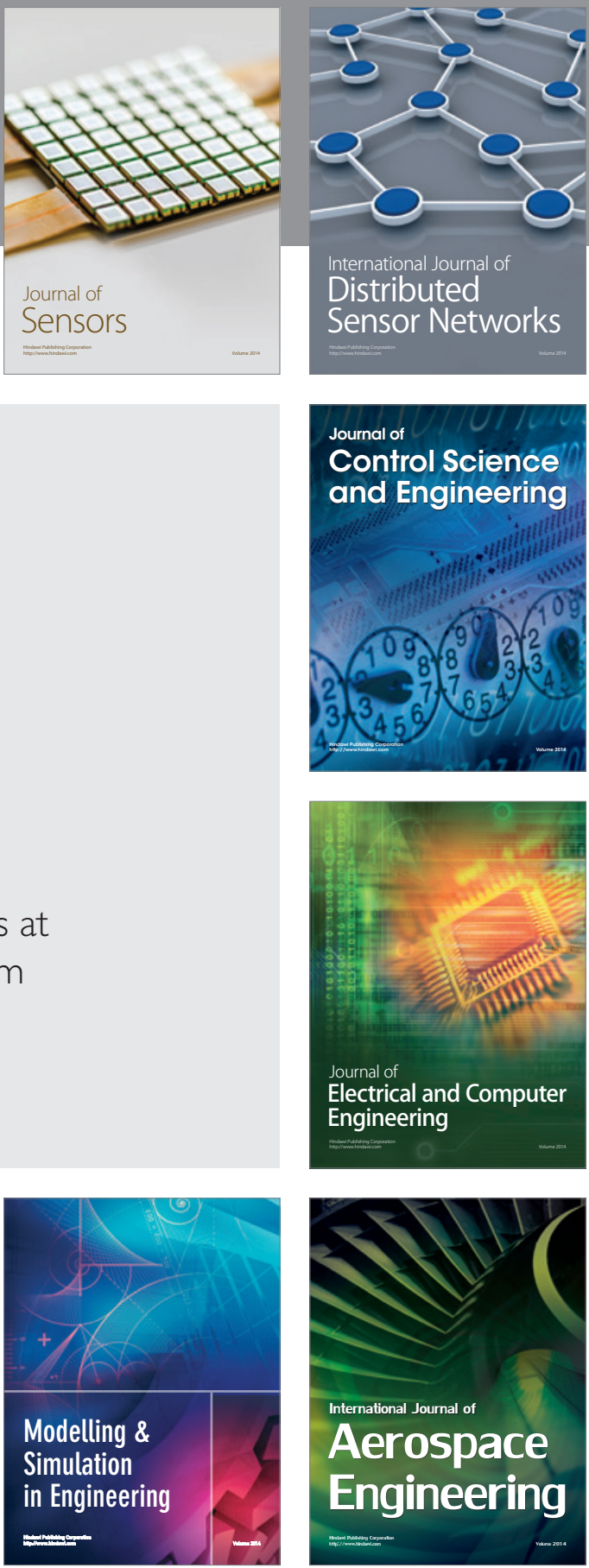

Journal of

Control Science

and Engineering
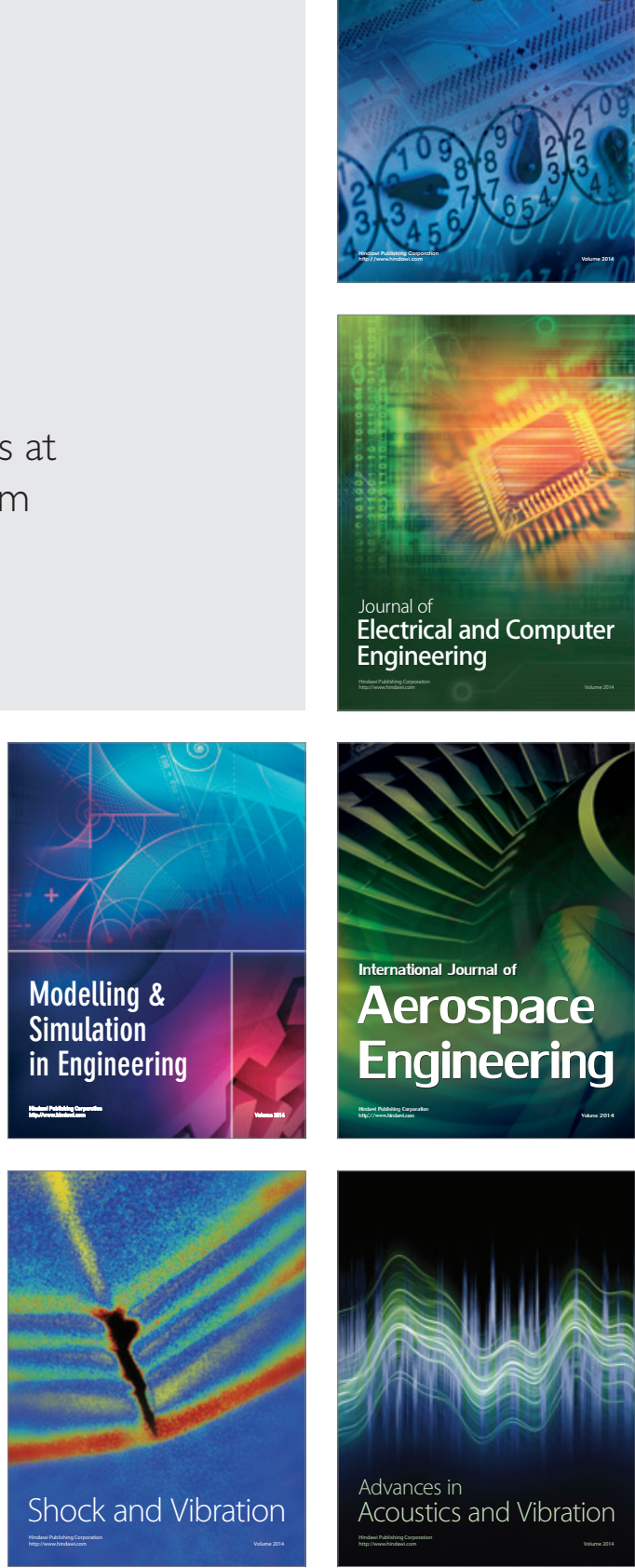